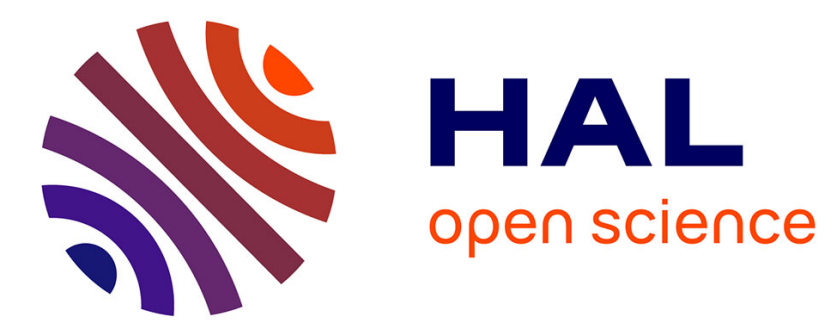

\title{
Impact of humate complexation on the adsorption of REE onto Fe oxyhydroxide
}

Mélanie Davranche, Olivier Pourret, Gérard Gruau, Aline N. Dia

\section{To cite this version:}

Mélanie Davranche, Olivier Pourret, Gérard Gruau, Aline N. Dia. Impact of humate complexation on the adsorption of REE onto Fe oxyhydroxide. Journal of Colloid and Interface Science, 2004, 277 (2), pp.271-279. 10.1016/j.jcis.2004.04.007 . hal-02265577

\section{HAL Id: hal-02265577 \\ https://hal.science/hal-02265577}

Submitted on 10 Aug 2019

HAL is a multi-disciplinary open access archive for the deposit and dissemination of scientific research documents, whether they are published or not. The documents may come from teaching and research institutions in France or abroad, or from public or private research centers.
L'archive ouverte pluridisciplinaire HAL, est destinée au dépôt et à la diffusion de documents scientifiques de niveau recherche, publiés ou non, émanant des établissements d'enseignement et de recherche français ou étrangers, des laboratoires publics ou privés. 
Impact of humate complexation on the adsorption of REE onto Fe oxyhydroxide

Mélanie Davranche ${ }^{1}$, Olivier Pourret, Gérard Gruau and Aline Dia

CAREN, Géosciences Rennes, UMR CNRS 6118, Campus de Beaulieu 35042 RENNES Cedex, France

Short running title: Impact of humate complexation on REE adsorption

${ }^{1}$ Author to whom correspondence should be addressed: melanie.davranche@univ-rennes1.fr, phone: +33223235 769, Fax: +33223235787 
Adsorption experiments of rare-earth elements (REE) onto hydrous ferric oxide (HFO) were performed to evaluate the impact of organic complexation on both REE(III) adsorption and Ce(III) oxidation rate. Scavenging experiments were performed at $\mathrm{pH} 5.2$ with $\mathrm{NaCl}$ and $\mathrm{NaNO}_{3}$ solutions containing either free REE (III) or REE(III)-humate complexes. The $\log \mathrm{K}_{\mathrm{d}}^{\mathrm{REE}}$ patterns obtained from HFO suspensions exhibit a slight positive Ce anomaly and an M-type lanthanide tetrad effect, in contrast with the partitioning between REE(III)humate complexes and HFO, which yields completely flat distribution patterns. The 'organic' partitioning runs yield $\log \mathrm{K}_{\mathrm{d}}^{\mathrm{REE}_{\text {organic }}} / \log \mathrm{K}_{\mathrm{d}}^{\mathrm{DOC}}$ ratios (DOC=Dissolved Organic Carbon) close to 1.0, implying that the REE(III) and humate remain bound to each other during the adsorption experiment. The lack of any positive Ce anomaly or M-type lanthanide tetrad effect in the organic experiments seems to reflect an anionic adsorption of the REE-humate complex. Adsorption onto HFO takes place via the humate side of the REE(III)-humate complexes. The oxidation of $\mathrm{Ce}(\mathrm{III})$ by $\mathrm{Fe}(\mathrm{III})$ and the proportion of surface hydroxyl groups coordinated to REE(III) at the HFO surface are the two most commonly invoked processes for explaining the development of positive Ce anomalies and the M-type tetrad lanthanide effect. However, such processes cannot proceed since the REE are not in direct contact with the HFO suspensions, the latter being shielded by PHA. The present results further complicate the use of Ce anomalies as reliable paleoredox proxies in natural precipitates. They are also further demonstration that organic matter may inhibit the lanthanide tetrad effect in geological samples.

Keywords: Ce anomaly, REE, humic acid, hydrous ferric oxide, oxidation/scavenging, ternary surface complex. 


\section{INTRODUCTION}

Hydrous ferric oxides (HFO) are often thought to control the mobility of trace elements in aqueous systems (1). Due to their large specific surface area, these mineral phases are indeed very effective scavengers of trace elements, and hence, they exert a key control on the concentration and migration of trace metals in aqueous systems (2). Interactions between trace elements and $\mathrm{Fe}$ oxyhydroxides depend upon various processes such as adsorption, surface precipitation, etc. and, in the particular case of the REE (Rare earth elements), oxidation/scavenging (3-5).

Understanding the REE distribution between Fe oxyhydroxides and aqueous solutions continues to be a major issue in REE studies on geochemical processes (6). Marine ferromanganese crusts are fairly enriched in REE and some of them exhibit large positive Ce anomalies (7-11). Deep-sea ferromanganese nodules, banded iron formations and $\mathrm{Fe}$ and $\mathrm{Mn}$ concretions in paleosols are geological deposits of major geochemical importance because they can record the REE signatures of ancient marine and fresh waters $(8,12-16)$.

Several authors have examined the adsorption processes of REE onto $\mathrm{Fe}$ oxyhydroxides and Mn oxides (3-5, 17, 18). Koeppenkastrop and De Carlo (3), presented the available data on sorption of REE from seawater, noting the close similarity between their

experimental determined $\mathrm{K}_{\mathrm{d}}^{\mathrm{REE}}$ values and those estimated from REE analyses of marine MnFe deposits and seawater samples. More recently, Bau (4) and Ohta and Kawabe (5) reported experimental investigations of the sorption of REE from low-salinity solutions. These authors showed that (i) Fe and Mn oxyhydroxides can both oxidize Ce(III) into $\mathrm{Ce}(\mathrm{IV})$, even though the resulting preferential enrichment of $\mathrm{Ce}$ as compared to its trivalent REE neighbours (the so-called positive Ce-anomaly) is much larger with Mn oxide than with Fe oxyhydroxide, and 
(ii) at $\mathrm{pH} \geq 5$, the M-type lanthanide tetrad effect appears on patterns of apparent REE distribution coefficients between Fe and Mn oxyhydroxides and aqueous solutions.

However, very little is known about the influence of organic matter on the sorptive properties of REE onto Fe oxyhydroxides. In a recent paper, we reported experimental $\mathrm{K}_{\mathrm{d}}$ between $\mathrm{Mn}$ oxide suspensions and weakly acid $(\mathrm{pH}=5.2) \mathrm{NaCl}$ and $\mathrm{NaNO}_{3}$ solutions containing REE as REE(III)-humate complexes (19). Under such conditions, the M-type lanthanide tetrad effect is easily suppressed and the oxidation of $\mathrm{Ce}$ by $\mathrm{Mn}$ oxide is greatly inhibited. The speciation of the REE partitioning between Fe oxyhydroxide and solution governs the REE behaviour in natural waters, as well as the oxidative scavenging of Ce(III). This behaviour has possible major implications on the use of Ce anomalies as paleo-redox proxies (20-24). The aim of this article is (i) to compare apparent $\mathrm{K}_{\mathrm{d}}{ }^{\mathrm{REE}}$ between hydrous ferric oxide (HFO) suspensions and synthetic solutions in which the REE(III) occurs alternatively as free REE(III) and REE(III)-humate complexes, and (ii) to examine the effect of organic complexation on $\mathrm{Ce}(\mathrm{III})$ oxidation and tetrad lanthanide effects in the presence of HFO.

\section{MATERIALS AND METHODS}

All chemicals used in this study were of analytical grade, and the solutions were all prepared with doubly de-ionized water (Milli-Q system, Millipore). Polyethylene containers used in the adsorption experiments were soaked in $10 \%$ Ultrapur $\mathrm{HNO}_{3}$ for $48 \mathrm{~h}$ at $60^{\circ} \mathrm{C}$, then rinsed with Milli-Q water for $24 \mathrm{~h}$ at $60^{\circ} \mathrm{C}$, to remove all possible REE contamination sources. Synthetic REE solutions were prepared from nitrate REE standards (10 ppm; Accu

Trace $^{\mathrm{TM}}$ Reference Standard). REE concentrations were determined by ICP-MS - HP 4500, Agilent Technologies at Rennes University (France) (See appendix). 


\section{HFO: Hydrous ferric oxide}

The HFO was synthesized according to Schwertmann and Cornell (25). 1.5 mole of $\mathrm{NaOH}$ (pellets) were added slowly to $1 \mathrm{~L}$ of a solution containing $0.5 \mathrm{M} \mathrm{Fe}\left(\mathrm{NO}_{3}\right)_{3}$, The solution was continuously bubbled with nitrogen to avoid carbonate precipitation. The HFO precipitate was centrifuged and washed several times with Milli-Q water, then dried at $20{ }^{\circ} \mathrm{C}$, sieved for homogenization and, finally, stored in a dessicator. The crystallographic structure of the HFO was checked by X-ray diffraction (XRD). The total number of [? negatively charged] surface sites of the solid phase was estimated using the solid cation exchange capacity (CEC) determined from the cobalthexammine method, ISO 11260 (26). Ions bound to the solid surface were exchanged with cobalthexammine ions, the CEC being taken as equal to the concentration of cobalthexammine ions removed from solution. Five grams of HFO were mixed with $10 \mathrm{~mL}$ of $0.017 \mathrm{M}$ cobalthexammine solution for $3 \mathrm{~h}$. The suspension was then centrifuged and the concentration of cobalthexammine ion remaining in solution was measured at $470 \mathrm{~nm}$ with a Shimadzu-160 A U.V.-spectrophotometer. The CEC of the HFO used in this study is $24.5 \mathrm{meq} / 100 \mathrm{~g}$.

The surface acidity constants were determined from potentiometric titrations of suspensions of 5 g.L ${ }^{-1} \mathrm{HFO}$ with $\mathrm{NaOH}(0.1 \mathrm{M})$ or $\mathrm{HNO}_{3}(0.1 \mathrm{M})$, with a $0.1 \mathrm{M} \mathrm{NaCl}$ solution as the supporting electrolyte (27). Titrations were carried out with a Metrohm 794 DMS Titrino apparatus equipped with a Metrohm combined $(3 \mathrm{M} \mathrm{KCl})$ glass electrode. The HFO acidity constants so obtained were as follows: $\mathrm{pK}_{\mathrm{a} 1}=6.77$ and $\mathrm{pK}_{\mathrm{a} 2}=8.56$, while $\mathrm{pH}_{\mathrm{zpc}}$ was 7.7 . 


\section{REE(III)-humate complexes}

Humate, referred to below as PHA (purified humic acid), was obtained from the synthetic Aldrich humic acid (Aldrich, H1,675-2) according to the process described by Vermeer et al. (28). The PHA obtained in this way is ash free and in its protonated form, with the following elemental composition (in weight percent): $\mathrm{C}=55.8 \%, \mathrm{O}=38.9 \%, \mathrm{H}=4.6 \%$, $\mathrm{N}=0.6 \%$. Purified humic acid has a mean molecular weight of 23000 Daltons (28). Prior to use, the freeze-dried PHA was resuspended overnight in a $\mathrm{NaOH}$ solution $(\mathrm{pH} 10)$ to ensure complete dissolution of the sample.

Rare-earth element-humate complexes were prepared as follows. Twenty mg of dissolved PHA were enclosed in a $250-\mathrm{mL}$ sodium-acetate dialysis bag with a pore size of 12 000-14 000 Daltons. The bag was introduced into a 5 ppb REE solution (corresponding to a molar concentration range of 36 to $29 \mathrm{nM}$ depending on the REE considered), the ionic strength being buffered at $10^{-3} \mathrm{M}$ with $\mathrm{NaCl}$ or $\mathrm{NaNO}_{3}$, and the $\mathrm{pH}$ at 7 with $\mathrm{HNO}_{3}$. Both $\mathrm{NaCl}$ and $\mathrm{NaNO}_{3}$ were used as neutral electrolytes (see below). The suspension was stirred for $48 \mathrm{~h}$ (equilibrium time determined from preliminary kinetic experiments), to allow equilibration and partitioning of the REE between the aqueous solution and the PHA suspension. The dialysis bag was then removed and the REE-PHA complexes recovered. The concentrations of REE in solution both inside and outside the dialysis bag were monitored vs. time in order to quantify the amount of REE complexed to PHA. Possible REE adsorption onto the dialysis bag was checked by analysing REE content of the membrane (dissolved by acidic digestion with $\mathrm{HNO}_{3} 14 \mathrm{~N}$ ). The results show that around 95\% (with $\mathrm{NaCl}$ ) or $60 \%$ (with $\mathrm{NaNO}_{3}$ ) of the REE initially present in the solution were complexed to the PHA. The remaining 5 or $40 \%$ were left in solution outside the membrane or adsorbed onto the dialysis 
bag. Moreover, complexation rates are found to increase slightly but regularly from the heavy to the light REE, which is consistent with the stability constant order determined by Takahashi (29) for REE(III)-humate complexes.

\section{Adsorption procedure}

Four time-series experiments were carried out - two with the REE occurring as REE(III)-humate complexes and two with the REE occurring as free, aqueous species - to assess the effects of organic complexation during REE(III) adsorption onto HFO. All suspensions were made up from $100 \mathrm{mg} . \mathrm{L}^{-1} \mathrm{HFO}$ left to equilibrate with a $0.001 \mathrm{M} \mathrm{NaCl}$ or $\mathrm{NaNO}_{3}$ aqueous solution at $\mathrm{pH}$ 5.2. Experiments were carried out at room temperature. The $\mathrm{pH}$ was monitored periodically with a $\mathrm{pH}$-meter and adjusted to 5.2 by addition of $\mathrm{HNO}_{3}$ (4.6 $\mathrm{N})$ or $\mathrm{NaOH}(4 \mathrm{~N})$. The $\mathrm{pH}$ value of 5.2 was chosen because it was sufficiently basic to promote adsorption processes, but low enough to avoid total REE sorption that might mask any eventual development of Ce anomaly (19).

The first set of experiments carried out with free REE(III) was essentially conducted to validate the experimental and analytical protocol used in this study. In the second and third series of experiments, the equilibration was made with the REE(III)-PHA complexes described above.

We can describe the adsorption behaviour of the REE using the apparent partition coefficient $\mathrm{K}_{\mathrm{d}}$, expressed in Eq. [1] as

$$
\mathrm{K}_{\mathrm{d}}=\frac{\mu \mathrm{g} \text { REE adsorbed } / \mathrm{g} \text { HFO }}{\mu \mathrm{g} \cdot \mathrm{mL}^{-1} \mathrm{REE} \text { in solution }}
$$

Suspension aliquots of about $10 \mathrm{ml}$ were sampled at predetermined time intervals and filtered in-line through $0.2 \mu \mathrm{m}$ cellulose acetate membranes (Sartorius). The REE concentrations were then measured to determine the $\mathrm{K}_{\mathrm{d}}^{\mathrm{REE}}$ variations. Sample aliquots used 
for REE determination in organic experiments were all immediately digested with sub-boiled nitric acid $\left(\mathrm{HNO}_{3} 14 \mathrm{~N}\right)$ at $100^{\circ} \mathrm{C}$, then resolubilized in $\mathrm{HNO}_{3} 0.4 \mathrm{~N}$ after complete evaporation in order to avoid interferences with organic matter during mass analysis.

REE concentrations were determined by ICP-MS at Rennes University. Precisions on individual REE concentrations and $\log K_{d}$ values are estimated at $\pm 2 \%$ (See Appendix ).

The adsorption behaviour of the REE(III)-humate complexes was also monitored by measuring the dissolved organic carbon (DOC) content. DOC measurements can be converted into apparent partition coefficients using Eq. [2]:

$$
\mathrm{K}_{\mathrm{d}}=\frac{\mu \mathrm{g} \text { DOC adsorbed } / \mathrm{g} \text { HFO }}{\mu \mathrm{g} \cdot \mathrm{mL}^{-1} \text { DOC in solution }}
$$

Dissolved organic carbon concentrations were determined at Rennes University using a Shimadzu 5000 TOC analyzer. The precision on DOC contents and $\log \mathrm{K}_{\mathrm{d}}^{\mathrm{DOC}}$ are better than $\pm 1.5 \%$.

\section{RESULTS AND DISCUSSION}

Description of $\log K_{d}^{R E E}$ and $\log K_{d}^{\text {DOC }}$ patterns

The time dependence of the sorption of free REE(III) and REE-PHA complexes onto HFO is presented in Figs 1 and 2, respectively. Both the organic and inorganic experiments exhibit a faster adsorption in runs conducted with $\mathrm{NaCl}$ solutions as compared with those conducted with $\mathrm{NaNO}_{3}$. However, the composition of the neutral electrolyte has no effect on the equilibrium $\log \mathrm{K}_{\mathrm{d}}^{\mathrm{REE}_{\text {inorganic }}}$ values. Adsorption kinetics were slowed down by a factor of two in organic experiments compared with runs where REE(III) occurred as free species. The 
values of equilibrium $\log \mathrm{K}_{\mathrm{d}}^{\mathrm{REE}_{\text {organic }}}$ are more closely grouped than the $\log \mathrm{K}_{\mathrm{d}}^{\mathrm{REE}_{\text {inorganic }}}$ equilibrium data. Ratios of $\log \mathrm{K}_{\mathrm{d}}^{\mathrm{REE}}$ organic $/ \log \mathrm{K}_{\mathrm{d}}^{\mathrm{DOC}}$ are close to 1.0 , indicating that the REE(III) and humate remain bound to each other during interaction of the REE(III)-humate

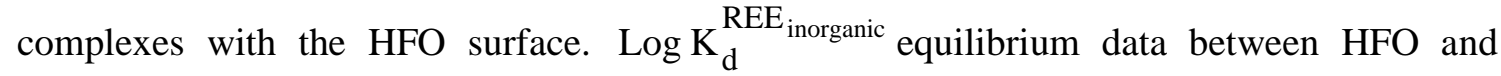
solutions containing free REE(III) are comparable to earlier values reported by Ohta and Kawabe (5) at similar $\mathrm{pH}$ conditions.

All inorganic patterns exhibit slight positive $\mathrm{Ce}$ anomalies and a clear M-type lanthanide tetrad effect (Fig. 3). The tetrad effect often corresponds to a very small discrete feature on the REE patterns of geological samples Mc Lennan (30). However, in the present study, the total uncertainty on the REE and Log $\mathrm{K}_{\mathrm{d}}^{\mathrm{REE}}$ is estimated at $2 \%$. In $\mathrm{NaNO}_{3}$ inorganic experiment, the difference between $\log \mathrm{K}_{\mathrm{d}}^{\mathrm{Eu}_{\text {inorganic }}}$ and $\log \mathrm{K}_{\mathrm{d}}^{\mathrm{Gd}_{\text {inorganic }}}$ is 0.2 , which corresponds to $5.5 \%$ of the $\log \mathrm{K}_{\mathrm{d}}^{\mathrm{Gd}_{\text {inorganic }}}$ value. This relative error of $5.5 \%$ is far higher than the uncertainty determined for analytical measures, confirming that the observed tetrad effect reflects a true feature rather than an analytical artifact.

Positive Ce anomalies and a clear M-type lanthanide tetrad effect were already apparent in the $\log \mathrm{K}_{\mathrm{d}}^{\mathrm{REE}}$ patterns obtained by Bau (4) and Ohta and Kawabe (5) under similar experimental conditions. $\mathrm{Ce}_{\text {inorganic }}$ anomaly values $(\mathrm{Ce} / \mathrm{Ce} *)$ as calculated by $\log \mathrm{K}_{\mathrm{d}}^{\mathrm{Ce}}-\left[\frac{\log \mathrm{K}_{\mathrm{d}}^{\mathrm{Pr}}+\log \mathrm{K}_{\mathrm{d}}^{\mathrm{La}}}{2}\right]$ range from 0.11 to 0.15 . However, organic patterns differ markedly from the former in showing no positive $\mathrm{Ce}$ anomaly $(\mathrm{Ce} / \mathrm{Ce} *=0.01)$ and no M-type lanthanide tetrad effect (Fig. 4). The general lack of a conspicuous "M"-shaped lanthanide tetrad effect in the organic patterns is very interesting and probably highly significant concerning the mechanism(s) of adsorption of the REE(III)-PHA complexes onto HFO. 
The complexation of REE(III) by humic acid has a large effect on $\mathrm{K}_{\mathrm{d}}^{\mathrm{REE}}$ equilibrium values. Time-series variations of $\log \mathrm{K}_{\mathrm{d}}^{\mathrm{REE}_{\text {organic }}}$ indicate that equilibrium is modified, $60 \mathrm{~h}$ under organic conditions v.s. $40 \mathrm{~h}$ in inorganic experiments (Figs. 1 and 2).

\section{Description of mechanisms}

These data support the earlier findings by Davranche et al. (19) that organic complexation may inhibit $\mathrm{Ce}(\mathrm{III})$ oxidation and prevent the development of a M-type lanthanide tetrad effect during interaction between dissolved REE(III) and Fe-Mn oxyhydroxides. REE patterns from the organic runs do not exhibit any Ce anomaly or M-type lanthanide tetrad effect whatever the supporting electrolyte (Fig. 4). Such results are clearly in strong contrast with the inorganic runs, implying that the mechanisms involved under organic conditions are distinctly different.

Bau (4) and Ohta and Kawabe (5) suggested that the formation and growth of an M-type tetrad effect might reflect a change in the coordination state of the REE(III) adsorbed onto Fe and $\mathrm{Mn}$ oxyhydroxides. They proposed that $\mathrm{REE}(\mathrm{III})$ adsorbed onto $\mathrm{MnO}_{2}$ are linked with hydroxyl ions, water molecules and oxygen that are bound to the $\mathrm{Mn}(\mathrm{IV})$. According to these authors, this coordination would explain the increase of a convex tetrad effect with $\mathrm{pH}$, by increasing the proportion of hydroxyl ions bound with REE(III). Similarly, Ce is oxidized to $\mathrm{Ce}$ (IV) by an oxidation/scavenging process involving dissolved $\mathrm{Ce}(\mathrm{III})$ and solid $\mathrm{Mn}-\mathrm{Fe}$ oxyhydroxides. Evidence for this oxidation process was given by Ohta and Kawabe (5), who determined the redox state of $\mathrm{Mn}$ in each of their experiments. However, REE and Ce must be in contact with the solid surface to allow both of these features to develop. The similarity of the $\log \mathrm{K}_{\mathrm{d}}^{\mathrm{REE}_{\text {organic }}}$ and $\log \mathrm{K}_{\mathrm{d}}^{\mathrm{DOC}}$ patterns (Figs. 1 and 2) show that REE and humate are 
strongly linked and that the bonding between these elements is maintained throughout the reaction. Cation ligand complexes, denoted as ML (with $\mathrm{M}$ and $\mathrm{L}$ representing the cation and the ligand, respectively), can adsorb onto a solid $(\equiv \mathrm{S})$ to form ternary surface complexes either as $\equiv \mathrm{S}-\mathrm{LM}$ (cation linked to the mineral surface over the ligand) or as $\equiv \mathrm{S}-\mathrm{O}-\mathrm{ML}$ (ligand linked to the surface over the cation) $(31,32)$. The formation of both types of complexes depend on whether the surface groups of the oxide can participate in exchanging their $\mathrm{OH}^{-}$with the cation-ligand complex. These reactions strongly depend on $\mathrm{pH}$. When $\mathrm{pH}$ is lower than the solid $\mathrm{pH}_{\mathrm{zpc}}(\mathrm{pH}$ at which the solid surface charge is globally neutral: i.e., the positive charges are equal to the negative charges), adsorption is of anionic type ( $\equiv \mathrm{S}-\mathrm{LM}$ ). When $\mathrm{pH}$ is higher than $\mathrm{pH}_{\mathrm{zpc}}$, the cationic type of adsorption $(\equiv \mathrm{S}-\mathrm{O}-\mathrm{ML})$ is promoted. The HFO used in the experiments exhibits a $\mathrm{pH}_{\mathrm{zpc}}$ value of 7.7 , while the experiments were carried out at 5.2. Consequently, this $\mathrm{pH}$ condition -much lower than the solid $\mathrm{pH}_{\mathrm{zpc}}{ }^{-}$ promotes anionic-type adsorption $\equiv \mathrm{S}-\mathrm{PHA}$ - REE, where REE are present as REE/PHA complexes. The complexes are bound to the HFO surface on their humate side (Eq. [3]):

$$
\equiv \mathrm{S}-\mathrm{OH}+\mathrm{REE}-\mathrm{PHA} \Leftrightarrow \equiv \mathrm{S}-\mathrm{PHA}-\mathrm{REE}+\mathrm{OH}^{-}
$$

This process accounts for the modification of $\log \mathrm{K}_{\mathrm{d}}^{\mathrm{REE}_{\text {organic }}}$ values in the organic experiment as compared with the inorganic runs (Figs. 1, 2 and Figs. 3, 4). These results are in good agreement with a recently completed study on the adsorption of REE-PHA onto $\mathrm{MnO}_{2}$ (19). Thus, the distribution of REE in the presence of organic complex is determined by the distribution of humate at the HFO surface. Takahashi et al. (33) obtained the same result in their study of the adsorption of $\mathrm{Cm}$ (III)-fulvate onto an acid-montmorillonite, even when using relatively low concentrations of organic matter. 
Consequences on using the Ce anomaly as a paleo-redox proxy

Taken together with the results obtained by Davranche et al. (19), the present study shows that the $\mathrm{Ce}$ anomaly can hardly be used as a paleo-redox proxy in organic-rich environments. This particularly applies to paleosols, where Ce anomalies have often been reported $(13,16,22)$ and authors have explored the possibility of using Ce depletions to reconstruct the redox state of paleosols at the time of their formation (e.g., 22). From a paleoclimatic point of view, we may consider that wet periods lead to the dominance of oxidizing conditions in paleosols - due to the continuous recharge of the soil solutions by oxygen-rich rainwater - a process that would stabilize both $\mathrm{Mn}$ and Fe oxydroxide phases in the weathering front. Just considering the inorganic experimental results of Bau (4) and Ohta and Kawabe (5), we would expect the development of either negative or positive $\mathrm{Ce}$ anomalies in paleosols formed under such conditions. However, these experimental results lead us to suppose that organic complexation can severely inhibit Ce(III) oxidation. This

calls into question the validity of using $\mathrm{Ce}$ anomalies as a reliable paleo-redox proxy in paleosols. The interplay between variable redox conditions and the REE(III) organic speciation is expected to lead to complex Ce anomaly patterns in paleosols. The behaviour of Ce might not unambiguously reflect the redox conditions at time of the soil genesis.

\section{SUMMARY}

Scavenging of dissolved REE(III)-PHA complexes by HFO was experimentally studied to elucidate further the role played by humate ligands in REE(III) adsorption and $\mathrm{Ce}(\mathrm{III})$ oxidation produced by $\mathrm{Fe}$ oxyhydroxides. The apparent $\log \mathrm{K}_{\mathrm{d}}^{\mathrm{REE}}$ patterns in $\mathrm{HFO}$ 
suspensions exhibit slight positive Ce anomalies and an M-type lanthanide tetrad effect. This is in contrast with the distribution patterns obtained between REE(III)-humate complexes and HFO, which are completely flat. These modifications are believed to reflect an anionic adsorption of the organic complex. The ternary complexes formed at the surface of the HFO represent structures in which the binding of the REE(III)-PHA with the HFO surface takes place on the humate side. Consequently, the humate ligand physically separates Ce(III) ions from the HFO catalysis surface, thus preventing their oxidation by $\mathrm{Fe}(\mathrm{III})$ and stopping the development of an M-type tetrad effect. The distribution of REE at the HFO surface is then governed by the behaviour of humic substances.

These data add further limitations to the use of Ce anomalies in reconstructing redox conditions in ancient geological systems. The present results, as well as those recently reported by Davranche et al. [19] for the $\mathrm{MnO}_{2}$ system, strongly suggest that use of this proxy could be rendered impossible in organic-rich systems such as paleosols.

\section{ACKNOWLEDGEMENTS}

We wish to thank the technical staff in Rennes for their assistance during the experimental and analytical work. This research was supported by the INSU-CNRS through Programme PNSE.

\section{REFERENCES}

[1] Davis, J.A., and Kent, D.B In: M.F. Hochella and A.F. White (Eds.), Mineral Interface Geochemistry, Mineralogical Society of America, Washington D. C., 1990, p.177.

[2] Dzombak, D.A., Morel, F.M.M., Surface Complexation Modeling, Hydrous Ferric Oxide, Wiley-Interscience, New York, 1990. 
[3] Koppenkastrop, D., and De Carlo, E.H., Chem. Geol. 95 (1992) 251.

[4] Bau, M., Geochim. Cosmochim. Acta 63 (1999) 67.

[5] Ohta, A., Kawabe, I., Geochim. Cosmochim. Acta. 65 (2001) 695.

[6] Elderfield, H., Upstill-Goddard, R., Sholkovitz, E. R., Geochim. Cosmochim. Acta 54 (1990) 971.

[7] Piper, D.Z., Geochim. Cosmochim. Acta 38 (1974)1007.

[8] Elderfield, H., Hawkersworth, C.J., Greaves, M.J., Calvert, S.E., Geochim. Cosmochim. Acta 45 (1981) 513.

[9] De Carlo, E.H., Mc Murthy, G.M., Chem. Geol. 95 (1992) 235.

[10] Bau, M., Koschinsky, A., Dulski, P., Hein, J.R., Geochim. Cosmochim. Acta 60 (1996) 1709.

[11] Ohta, A., Ishii, S., Sakakibara, M., Mizuno, A., Kawabe, I., Geochem. J. 33 (1999) 399.

[12] Goldberg, E.D., Koide, M., Schmitt, R.A., Schmith, R.H. J. Geophys. Res. 68 (1963) 4209.

[13] Rankin, P. C., Child, C. W., Chem. Geol. 18 (1976) 54.

[14] Shimizu, H., Umemoto, N., Masuda, A., Appel, P.W.U., Geochim. Cosmochim. Acta 54 (1990) 1147.

[15] Alibert, C., McCulloch, M.T., Geochim. Cosmochim. Acta 57 (1993) 187.

[16] Braun, J. J., Viers, J., Dupré, B., Polvé, M., Ndam, J., Muller, J. P., Geochim. Cosmochim. Acta 62 (1998) 273.

[17] Koeppenkastrop, D., DE Carlo, E.H., Roth, M., J. Radioanal. Nuclear Chem. 2 (1991) 337.

[18] De Carlo, E.H., Wen, X.Y., Irving, M., Aquatic Geochem. 3 (1998) 357.

[19] Davranche, M., Gruau, G., Dia, A., Le Coz-Bouhnik, M., Revised version submitted to Geochim. Cosmochim. Acta (2004). 
[20] Wright, J., Schrader, H., Holser, W.T., Geochim. Cosmochim. Acta 51 (1987) 631.

[21] Macleod, K.G., Irving, A.J., J. Sedim. Res. 66 (1996) 948.

[22] Gallet, S., Jahn, B.M., Torii, M., Chem. Geol. 133 (1996) 67.

[23] Holser, W.T., Paleogeol. Paleoclim. Paleoecol. 132 (1997) 309.

[24] Morad, S., Felitsyn, S., Sed. Geol. 143 (2001) 259.

[25] Schwertmann, U., Cornell, R. M., Iron Oxide in the Laboratory, Preparation and Characterization. VCH Verlag, Weinheim, 1996.

[26] AFNOR, Qualité des Sols, AFNOR, Paris, 1994.

[27] Davranche, M., Lacour, S., Bordas, F., Bollinger, J-C., J. Chem. Edu. 80 (2003) 76.

[28] Vermeer, A.W.P., Van Riemdjik, W.H., Koopal, L.K., Langmuir 14 (1998) 2810.

[29] Takahashi, Y., Minai, Y., Makide, Y., Ambe, F., Geochim. Cosmochim. Acta 63 (1999) 815.

[30] McLennan, S.M., Geochim. Cosmochim. Acta 58 (1994) 2025.

[31] Schindler, P.W., In: M.F. Hochella and A.F. White (Eds), Mineral-Water Interface Geochemistry. Mineralogical Soc. of Am., Whashington D.C., 1990, p. 281.

[32] Nowack, B., Sigg, L., J. Colloid Interface Sci. 177 (1996) 106.

[33] Takahashi, Y., Kimura, T., Minai, Y., Geochim. Cosmochim. Acta 66 (2002) 1.

[34] Yeghicheyan, D., Carignan, J., Valladon, M., Bouhnik-Le Coz, M., Le Cornec, F., Castrec-Rouelle, M., Robert, M., Aquilina, L., Aubry, E., Churlaud, C., Dia, A., Deberdt, S., Dupré, B., Frédier, R., Gruau, G., Hénin, O., De Kersabiec, A-M., Petitjean, P., Serrat, E., Geostand. Newslett., 25 (2002) 465. 

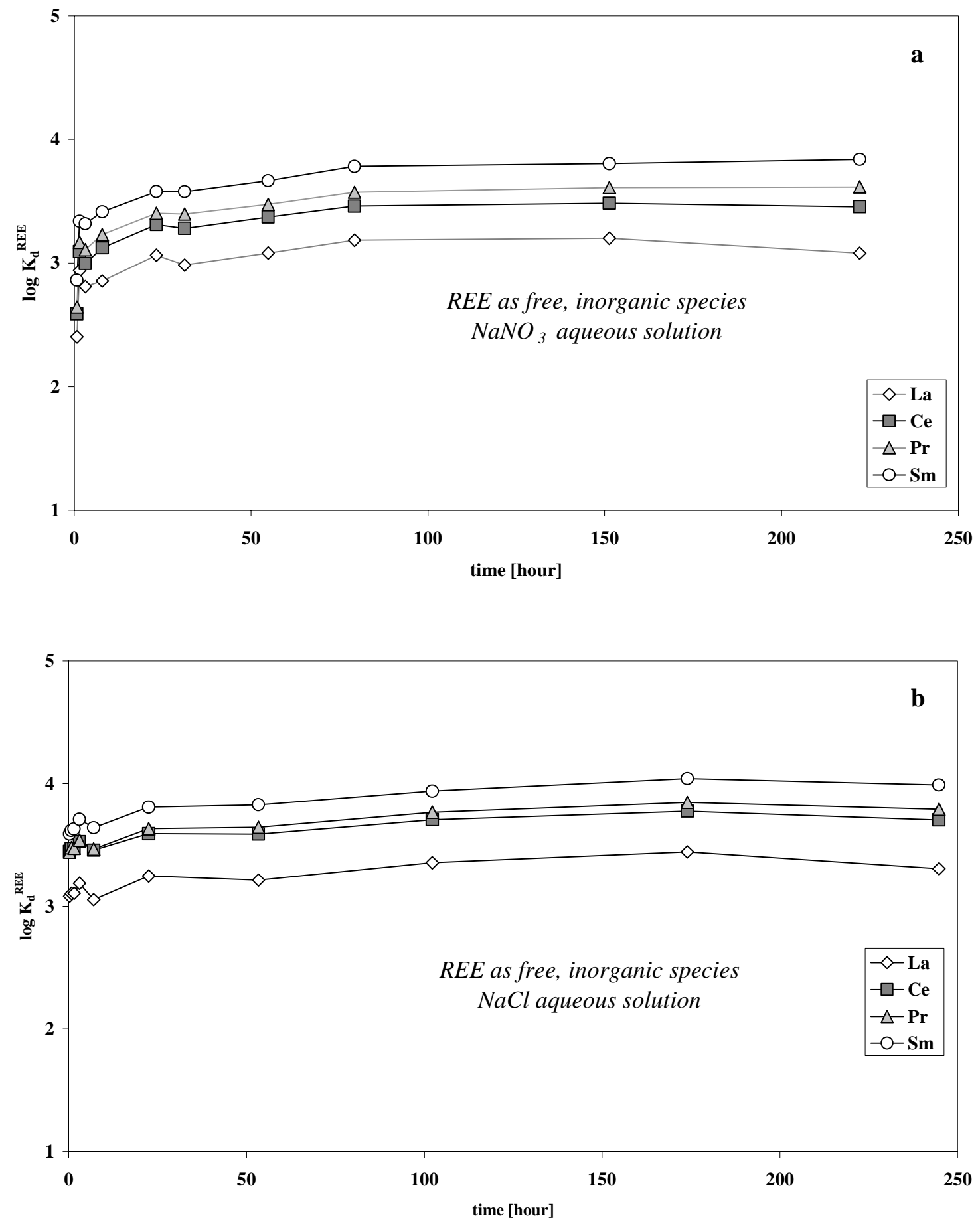

Fig 1

Mélanie Davranche, Olivier Pourret, Gérard Gruau, Aline Dia 

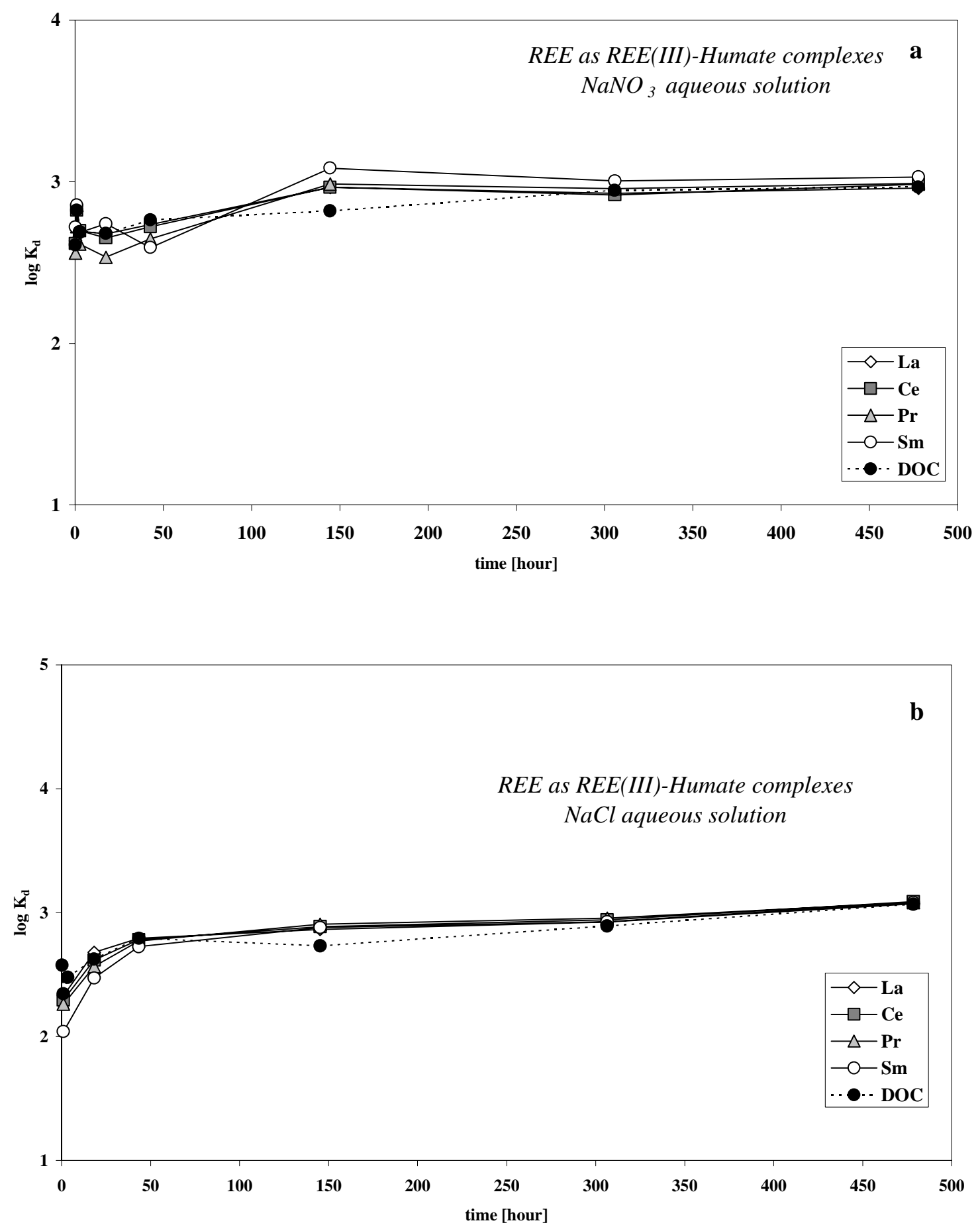

Fig. 2

Mélanie Davranche, Olivier Pourret, Gérard Gruau, Aline Dia 


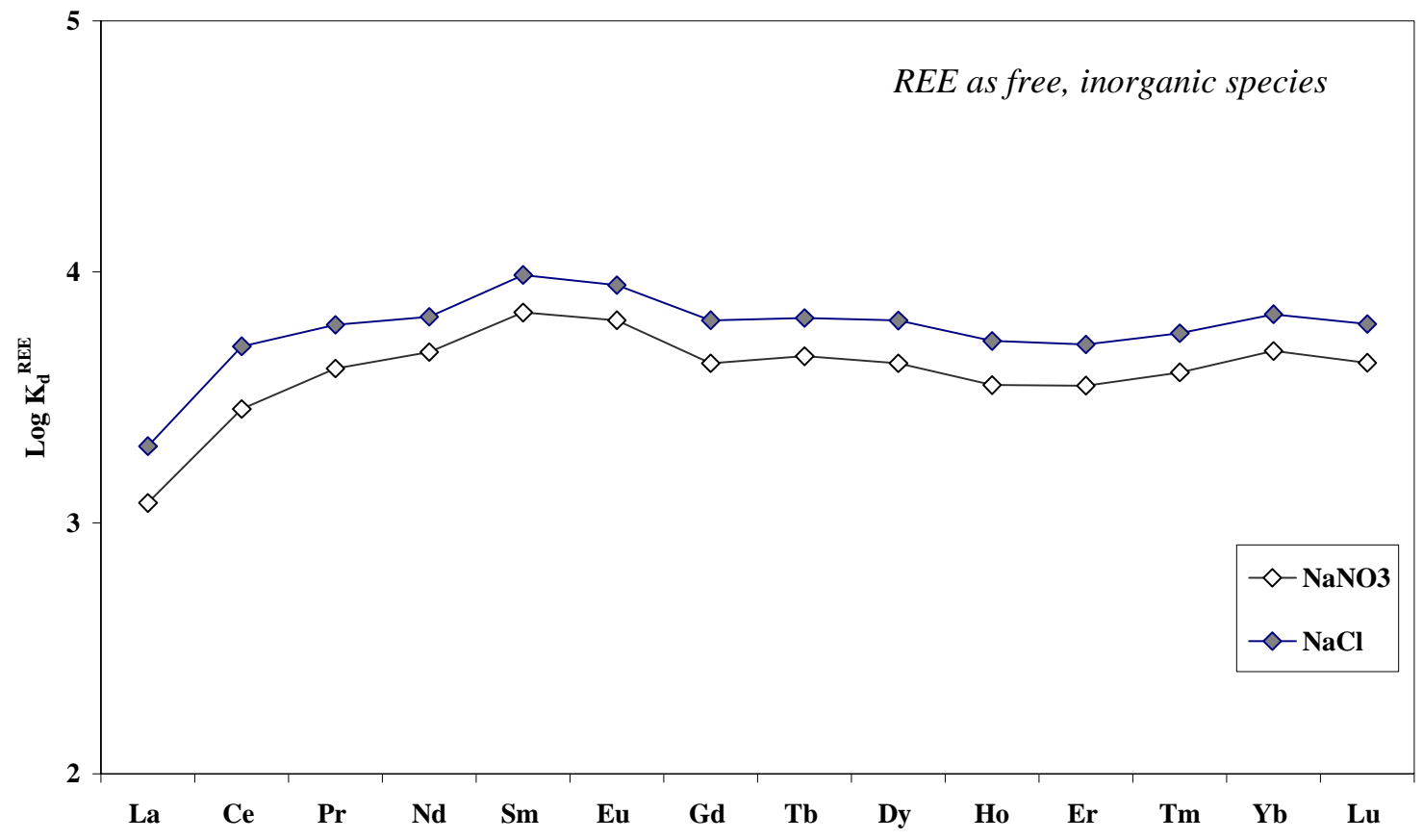

Fig.3

Mélanie Davranche, Olivier Pourret, Gérard Gruau, Aline Dia 


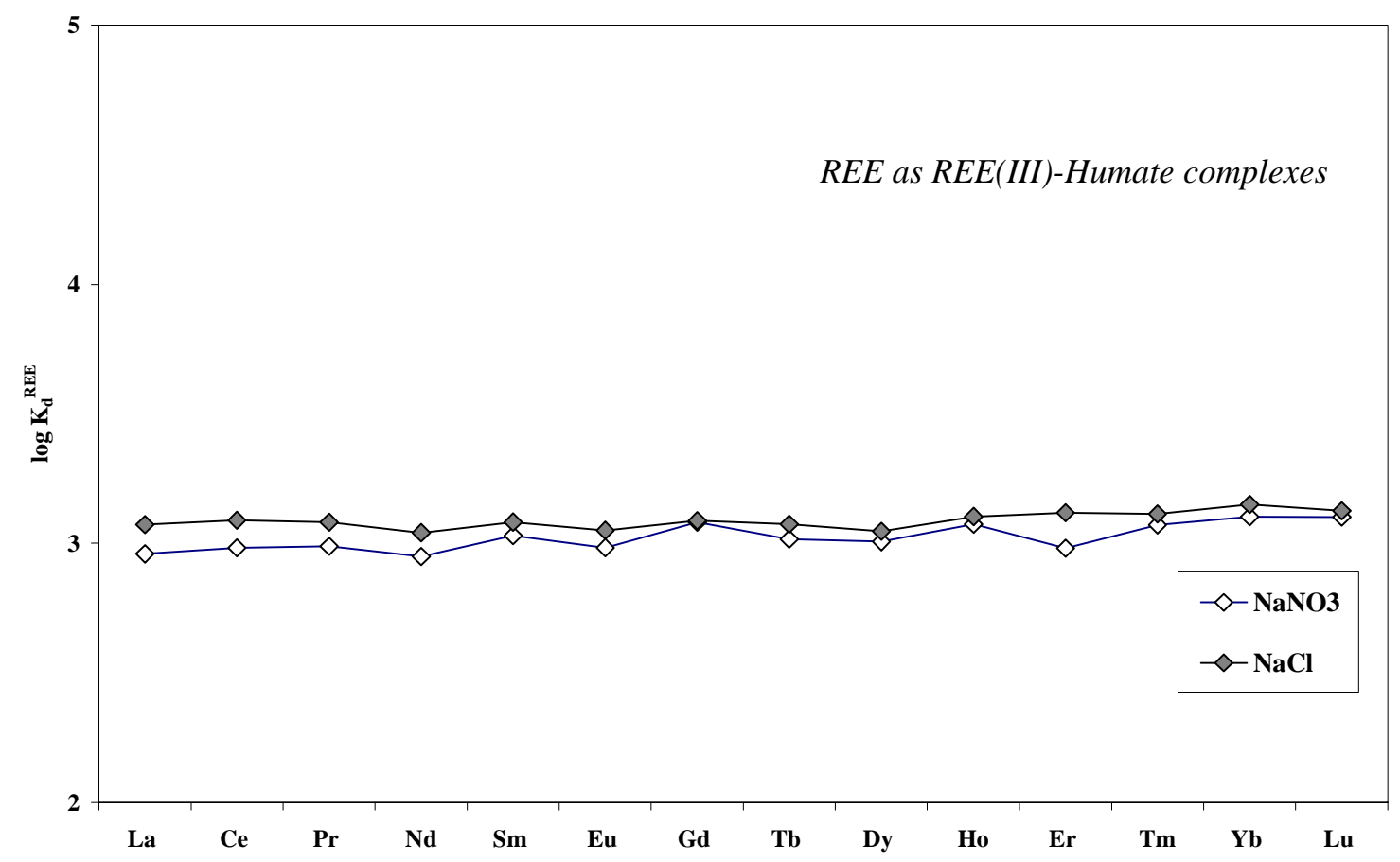

Fig.4

Mélanie Davranche, Olivier Pourret, Gérard Gruau, Aline Dia 


\section{Figures captions}

Fig. 1. $\log \mathrm{K}_{\mathrm{d}}^{\mathrm{REE} \text { inorganic }}$ values between $\mathrm{HFO}$ suspensions and (a) $\mathrm{NaCl}$, and (b) $\mathrm{NaNO}_{3}$ aqueous solutions, plotted vs. equilibrium time.

Fig. 2. $\log \mathrm{K}_{\mathrm{d}}^{\mathrm{REE} \text { organic }}$ and $\log \mathrm{K}_{\mathrm{d}}^{\mathrm{DOC}}$ values between HFO suspensions and (a) $\mathrm{NaCl}$, and (b) $\mathrm{NaNO}_{3}$ aqueous solutions, plotted vs. equilibrium time

Fig. 3. Patterns of equilibrium $\log \mathrm{K}_{\mathrm{d}}^{\mathrm{REE} \text { inorganic }}$ values derived from time-series experiments with aqueous solutions of $\mathrm{NaNO}_{3}$ (open symbols) and $\mathrm{NaCl}$ (full symbols). Note the slight positive Ce anomaly and the conspicuous lanthanide tetrad effect.

Fig. 4. Patterns of equilibrium $\log \mathrm{K}_{\mathrm{d}}^{\mathrm{REE} \text { organic }}$ derived from time-series experiments with solutions of $\mathrm{NaNO}_{3}$ (open symbols) and $\mathrm{NaCl}$ (full symbols). Note the flatness of the $\log \mathrm{K}_{\mathrm{d}}^{\mathrm{REE}}$ patterns. 


\section{Appendix - REE analyses}

Rare earth concentrations were determined by ICP-MS (Agilent Technologies ${ }^{\odot}$ HP4500) at the Rennes University (France). Normal plasma conditions were used, with the instrumental parameters reported in Table 1.

\section{TABLE 1}

\begin{tabular}{ll}
\multicolumn{2}{l}{ Instrumental and data acquisition parameters } \\
\hline RF Power & $1360 \mathrm{~W}$ \\
\hline Plasma gas & $15 \mathrm{~L} / \mathrm{min}$ \\
Auxiliary gas & $1.0 \mathrm{~L} / \mathrm{min}$ \\
Carrier gas & $1.13 \mathrm{~L} / \mathrm{min}$ \\
\hline Nebulizer type & $\mathrm{Cross}-\mathrm{flow}$ \\
Spray chamber $\mathrm{T}^{\circ}$ & $2{ }^{\circ} \mathrm{C}$ \\
\hline $\mathrm{Integration} \mathrm{time}$ & $3 \mathrm{~s} / \mathrm{mass}$ \\
\hline $\mathrm{CeO}^{+} / \mathrm{Ce}^{+}$ & $0.6 \%$ \\
$\mathrm{Ce}^{++} / \mathrm{Ce}^{+}$ & $1 \%$ \\
\hline
\end{tabular}

Quantitative analyses were performed using a conventional external calibration procedure. Three external standard solutions having REE concentrations corresponding to the samples were prepared from a multi-REE standard solution (Accu Trace ${ }^{\mathrm{TM}}$ Reference, 10 mg. $L^{-1}$, USA). Indium was added to all samples as an internal standard at a concentration of $0.87 \mu \mathrm{M}(100 \mathrm{ppb})$ to correct for instrumental drift and possible matrix effects. Indium was also added to the external standard solutions. Calibration curves were calculated from measured REE/Indium intensity ratios. 
Detection limits (DL) of the Agilent Technologies ICP-MS set up at Rennes University (Table 2) were calculated using the following equation:

$$
D L\left(p m o l . L^{-1}\right)=\frac{3 S D \cdot C}{S-B}
$$

$\mathrm{SD}$ is the standard deviation obtained during instrumental blank measurements, $\mathrm{C}$ the REE concentration of a standard solution (between 29 and $36 \mathrm{pM}$ depending on the REE), S and B the ion counts measured during standard solution and instrumental blank analyses, respectively.

TABLE 2

Detection limits and chemical blanks (in pM) measured during the course of the study

\begin{tabular}{|c|c|c|}
\hline Isotope & DL & Chemical Blanks \\
\hline La 139 & 1.15 & 4.37 \\
\hline $\mathrm{Ce} 140$ & 3.21 & 5.71 \\
\hline $\operatorname{Pr} 141$ & 0.64 & 2.35 \\
\hline Nd 146 & 3.54 & 7.28 \\
\hline Sm 147 & 5.52 & 0.64 \\
\hline Eu 153 & 0.92 & 0.76 \\
\hline Gd 158 & 2.67 & 2.07 \\
\hline Tb 159 & 0.38 & 1.50 \\
\hline Dy 163 & 1.29 & 2.76 \\
\hline Ho 165 & 0.49 & 1.08 \\
\hline Er 166 & 1.26 & 0.88 \\
\hline Tm 169 & 0.59 & 1.27 \\
\hline Yb 174 & 1.44 & 1.14 \\
\hline Lu 175 & 0.51 & 0.85 \\
\hline
\end{tabular}

DL: Detection Limits 
Chemical blanks of individual REE were all lower than $10 \mathrm{pM}$, which is a negligible value (Table 2) three to four orders of magnitude lower than the concentrations measured in the synthetic solutions used in the adsorption experiments.

Isobaric interferences due to the formation and ionisation of oxides and/or hydroxides in the ICP-MS can modify the determination of $\mathrm{Sm}, \mathrm{Eu}, \mathrm{Gd}$ and $\mathrm{Tb}$ concentrations. The interference list is given in Table 3, along with the equations used at Rennes to correct REE concentrations from this potential source of error. Note that $\mathrm{Ce}$ and its neighbours La and $\mathrm{Pr}$ and thus the calculated value of the Ce anomaly as well - are unaffected by isobaric interference problems. There was no need to correct $\mathrm{Eu}$ and $\mathrm{Sm}$ for $\mathrm{BaO}$ and/or $\mathrm{BaOH}$ interference because our synthetic solutions did not contain any Ba.

TABLE 3

Summary of isobaric interferences encountered during REE analysis and correction equations used at Rennes University to correct measured concentrations for this effect

\begin{tabular}{|c|c|c|}
\hline Isotope & Interference & Correction \\
\hline${ }^{147} \mathrm{Sm}^{+}$ & ${ }^{130} \mathrm{BaOH}^{+}$ & negligible \\
\hline${ }^{153} \mathrm{Eu}^{+}$ & ${ }^{137} \mathrm{BaO}^{+} ;{ }^{136} \mathrm{BaOH}^{+}$ & $\mathrm{Eu}[153]=\operatorname{Int}[153]-\frac{{ }^{153}(\mathrm{BaO}, \mathrm{BaOH})}{137 \mathrm{Ba}} \times \operatorname{Int}[137]$ \\
\hline $158 \mathrm{Cu}^{+}$ & ${ }^{142} \mathrm{CeO}^{+} ;{ }^{142} \mathrm{NdO}^{+}$ & $\operatorname{Gd}[158]=\operatorname{Int}[158]-\frac{158(\mathrm{PrOH})}{141_{\mathrm{Pr}}} \times \operatorname{Int}[141]-$ \\
\hline Ud & ${ }^{141} \mathrm{PrOH}^{+}$ & $\frac{{ }^{158}(\mathrm{CeO})}{140 \mathrm{Ce}} \times \operatorname{Int}[140]-\frac{158(\mathrm{NdO})}{142_{\mathrm{Nd}}} \times \operatorname{Int}[142]$ \\
\hline${ }^{159} \mathrm{~Tb}^{+}$ & ${ }^{143} \mathrm{NdO}^{+}$ & $\mathrm{Tb}[159]=\operatorname{Int}[159]-\frac{159(\mathrm{NdO})}{143_{\mathrm{Nd}}} \times \operatorname{Int}[143]$ \\
\hline
\end{tabular}


The amplitude and efficiency of the Gd and $\mathrm{Tb}$ corrections can be evaluated from Table 4, where we present measured and corrected concentrations of Gd and $\mathrm{Tb}$ measured for the SLRS-4 water geostandard along with reference data (34). The correction amplitudes are moderate, being $6 \%$ for $\mathrm{Gd}$ and only $2 \%$ for $\mathrm{Tb}$. The corrected values in both cases show relative discrepancies of $\leq 2.5 \%$, thus lying within the range of the reference values published for the SLRS-4 water geostandard (34). These values should be regarded as maximum values for the results presented here, since the ratios of [Interfering Element]/[Interfered Element] are close to unity in our synthetic solutions, as against 10-65 in the SLRS-4 geostandard.

\section{TABLE 4}

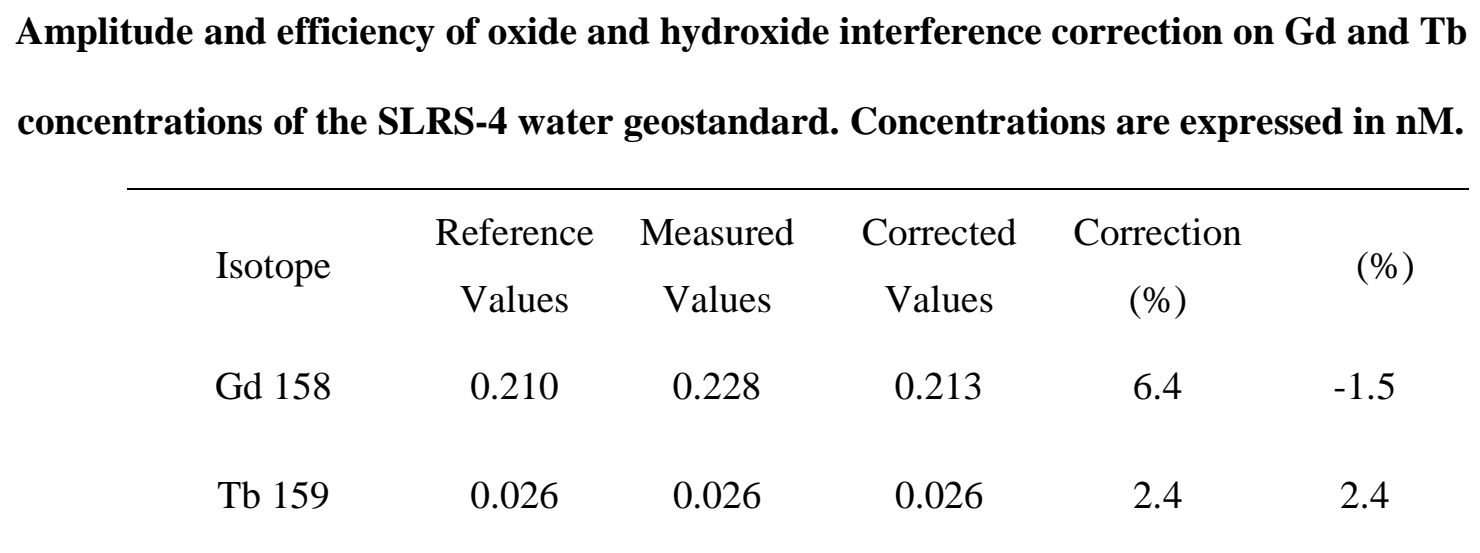

\section{: Relative discrepancy between corrected and reference values}

Reference concentrations are from Yeghicheyan et al. (34)

Finally, we can check the overall validity of the results using Table 5, which reports duplicate analyses of the synthetic solutions. Table 6 reports the concentrations of the SLRS- 4 standard compared with published reference values (34). From these two tables, and from an analysis of the efficiency of the correction procedure used to correct the REE results for oxide and hydroxide isobaric interferences, we estimate the total uncertainty on the REE results presented here at $\pm 2 \%$. 


\section{TABLE 5}

Duplicate analyses of the synthetic solutions used in the inorganic adsorption experiments.

\section{Concentrations are expressed in $\mathbf{n M}$.}

\begin{tabular}{|c|c|c|c|c|c|c|}
\hline & \multicolumn{3}{|c|}{$\mathrm{NaNO}_{3}$} & \multicolumn{3}{|c|}{$\mathrm{NaCl}$} \\
\hline Isotope & $\begin{array}{l}\text { Average } \\
(n=2)\end{array}$ & SD & $\mathrm{RSD} \%$ & $\begin{array}{c}\text { Average } \\
(n=2)\end{array}$ & $\mathrm{SD}$ & RSD \% \\
\hline La 139 & 35.07 & 0.16 & 0.46 & 37.41 & 0.06 & 0.17 \\
\hline Ce 140 & 34.24 & 0.10 & 0.29 & 36.37 & 0.13 & 0.35 \\
\hline $\operatorname{Pr} 141$ & 34.85 & 0.09 & 0.24 & 37.22 & 0.10 & 0.28 \\
\hline $\mathrm{Nd} 146$ & 33.87 & 0.06 & 0.19 & 36.66 & 0.01 & 0.02 \\
\hline Sm 147 & 32.62 & 0.07 & 0.22 & 35.08 & 0.02 & 0.06 \\
\hline Eu 153 & 31.64 & 0.04 & 0.12 & 34.49 & 0.00 & 0.00 \\
\hline Gd 158 & 30.91 & 0.03 & 0.08 & 33.63 & 0.04 & 0.11 \\
\hline Tb 159 & 31.19 & 0.03 & 0.09 & 34.11 & 0.03 & 0.08 \\
\hline Dy 163 & 29.60 & 0.02 & 0.06 & 32.34 & 0.04 & 0.11 \\
\hline Ho 165 & 29.58 & 0.04 & 0.14 & 32.62 & 0.04 & 0.12 \\
\hline Er 166 & 28.81 & 0.02 & 0.07 & 31.58 & 0.03 & 0.09 \\
\hline Tm 169 & 28.67 & 0.07 & 0.26 & 31.78 & 0.04 & 0.14 \\
\hline $\mathrm{Yb} 174$ & 28.25 & 0.04 & 0.14 & 31.41 & 0.08 & 0.24 \\
\hline Lu 175 & 27.41 & 0.03 & 0.13 & 30.41 & 0.04 & 0.13 \\
\hline
\end{tabular}

SD: Standard Deviation

RSD\%: Relative Standard Deviation $=($ SD/Mean Value $) * 100$

TABLE 6 
Comparison of the analytical accuracy of the Agilent Technology ${ }^{\odot}$ HP4500 ICP-MS set up at Rennes University against published reference values of the SLRS-4 water geostandard. Concentrations are expressed in nM.

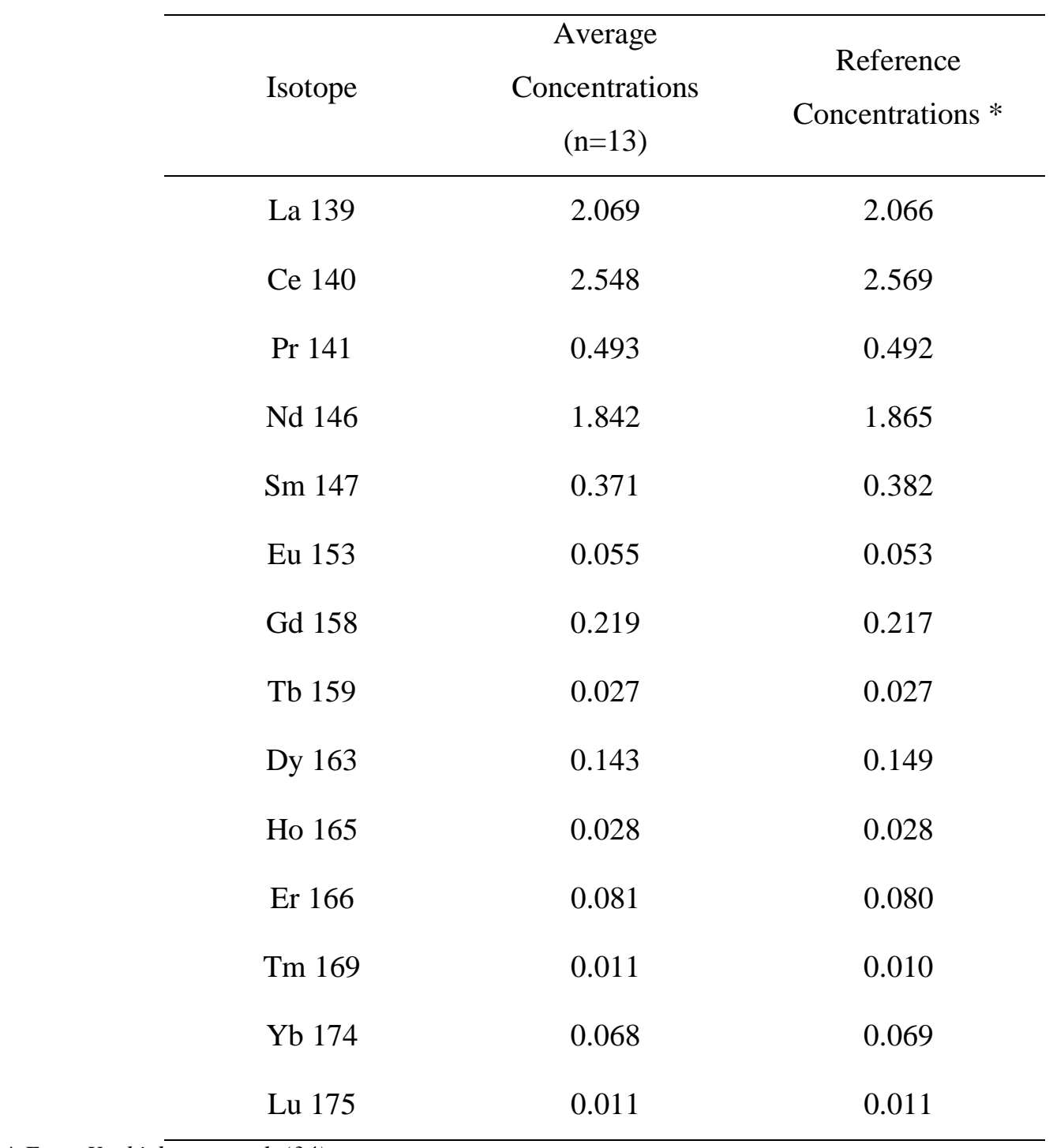

* From Yeghicheyan et al. (34) 